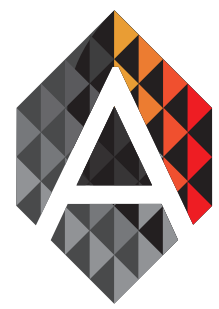

ADCAIJ: Advances in Distributed Computing and Artificial Intelligence Journal Regular Issue, Vol. 7 N. 2 (2018), 43-52

eISSN: $2255-2863$

DOI: http://dx.doi.org/10.14201/ADCAIJ2018724352

\title{
A Comparison of the $\mathrm{YC}_{\mathrm{B}} \mathrm{C}_{\mathrm{R}}$ Colour Space with Gray Scale for Face Recognition for Surveillance Applications
}

\author{
Jamal Ahmad Darghama, Ali Chekima ${ }^{\mathrm{a}}$, Ervin Gubin Mounga \\ and Segiru Omatu ${ }^{\mathrm{b}}$
}

a Fakulti Kejuruteraan, Universiti Malaysia Sabah, Jalan UMS, 88400 Kota Kinabalu, Sabah, Malaysia.
bFaculty of Engineering, Department of Electronics, Information and Communication Engineering, Osaka
Institute of Technology, 5-16-1, Omiya, Asahi-ku, Osaka, 535-8585, Japan.
jamalad@ums.edu.my,chekima@ums.edu.my,menirva.com@gmail.com,omatu@rsh.oit.ac.jp

\begin{tabular}{|c|c|}
\hline KEYWORD & ABSTRACT \\
\hline $\begin{array}{l}\text { Principal } \\
\text { Component } \\
\text { Analysis; YCBCR } \\
\text { colour space; } \\
\text { face recognition; } \\
\text { surveillance } \\
\text { applications }\end{array}$ & $\begin{array}{l}\text { Face recognition is an important biometric method because of its potential applica- } \\
\text { tions in many fields, such as access control and surveillance. In this paper, the perfor- } \\
\text { mance of the individual channels from the YCBCR colour space on face recognition } \\
\text { for surveillance applications is investigated and compared with the performance of } \\
\text { the gray scale. In addition, the performance of fusing two or more colour channels is } \\
\text { also compared with that of the gray scale. Three cases with different number of train- } \\
\text { ing images per persons were used as a test bed. It was found out that, the gray scale } \\
\text { always outperforms the individual channel. However, the fusion of CBxCR with any } \\
\text { other channel outperforms the gray scale when three images of the same class from the } \\
\text { same database are used for training. Regardless of the cases used, the CBxCR channel } \\
\text { always gave the best performance for the individual colour channels. It was found } \\
\text { that, in general, increasing the number of fused channels increases the performance of } \\
\text { the system. It was also found that the gray scale channel is the better choice for face } \\
\text { recognition since it contain better quality edges and visual features which are essential } \\
\text { for face recognition. }\end{array}$ \\
\hline
\end{tabular}

\section{Introduction}

Face detection and face recognition are growing biometric research fields because of their potential applications as important tools for many applications such as security surveillance and human-computer interaction. There are several reports that have reported the effect of colour spaces in biometric fields. Karimi and Devroye (2007) reported that using colour images with PCA-based face recognition system improves the recognition accuracy. Chaves-González et al. (2010) investigated the effect of colour spaces for face detection application using RGB, CMY, YUV, YIQ, $\mathrm{YP}_{\mathrm{B}} \mathrm{P}_{\mathrm{R}}, \mathrm{YC}_{\mathrm{B}} \mathrm{C}_{\mathrm{R}}, \mathrm{YC}_{\mathrm{G}} \mathrm{C}_{\mathrm{R}}, \mathrm{YD}_{\mathrm{B}} \mathrm{D}_{\mathrm{R}}, \mathrm{HSV}$ - or HSI - and CIE-XYZ. They tested 15 coloured frontal face images of different people obtained from the $\mathrm{AR}$ face database. They found out that using the colour

Jamal Ahmad Dargham, Ali Chekima, Ervin Gubin Moung and Segiru Omatu

A Comparison of the $\mathrm{YC}_{\mathrm{B}} \mathrm{C}_{\mathrm{R}}$ Colour Space with Gray Scale for Face Recognition for Surveillance Applications
ADCAIJ: Advances in Distributed Computing and Artificial Intelligence Journal Regular Issue, Vol. 7 N. 2 (2018), 43-52 eISSN: 2255-2863 - http://adcaij.usal.es Ediciones Universidad de Salamanca - CC BY NC DC 
information can improve the accuracy of the biometric system and reported that HSV colour space is the best one for skin detection with a success rate of $95.06 \%$. Yoo et al. (2007) investigated the effect of colour spaces (RGB, HSV, $\mathrm{YC}_{B} \mathrm{C}_{\mathrm{R}}$, and $\mathrm{YC}_{\mathrm{G}} \mathrm{C}_{\mathrm{R}}$ ) for face recognition. They reported that the $\mathrm{YC}_{\mathrm{B}} \mathrm{C}_{\mathrm{R}}$ colour space gives the best performance ( $92.3 \%$ correct recognition) when tested on the colour FERET database using PCA-based face recognition method. Chelali et al. (2015) proposed a PCA-based face recognition system that uses the segmented skin region of the face as the features for their system. Three colour spaces were investigated for skin region segmentation; RGB, HSV, and $\mathrm{YC}_{\mathrm{B}} \mathrm{C}_{\mathrm{R}}$. They used three databases for their experiment, two in a controlled environment with the same illumination and background (Computer Vision Center database and LCPTS Facial database), and the third database (CALTECH database) in an uncontrolled environment that present a variation in illumination, pose and background. The best reported recognition rate $(96 \%)$ is obtained when the $\mathrm{YC}_{B} \mathrm{C}_{R}$ colour space is used. As can be seen from the review, there are evidence that using colour can enhance face recognition systems and that most researchers reported that the $\mathrm{YC}_{\mathrm{B}} \mathrm{C}_{\mathrm{R}}$ colour space gives better recognition rate than other colour spaces. Since, we have used gray scale images obtained from colour images in our previous work (Dargham et al., 2015), in this paper a comparison of the performance of the $\mathrm{YC}_{\mathrm{B}} \mathrm{C}_{\mathrm{R}}$ colour space with gray scale for face recognition for surveillance application is carried out. In addition, an investigation of which channel or combination of channels from the $\mathrm{YC}_{\mathrm{B}} \mathrm{C}_{\mathrm{R}}$ colour space gives the best performance is carried out.

\section{Surveillance Dataset and Database Preparation}

The ChokePoint Dataset (National ICT Australia Limited, 2014) is one of the freely available surveillance databases under real-world surveillance conditions. It is a collection of surveillance videos of 25 persons in portal 1 and 29 persons in portal 2. Portal 2 dataset was used for database preparation since it has more subjects compared to portal 1. Portal 2 dataset consists of two sub datasets; Portal 2 Entering scene dataset (P2E) and Portal 2 Leaving scene dataset (P2L). P2L dataset contains better quality frontal faces. Thus, P2L dataset were selected for database preparation for all experiments. Although the video images were captured in four sessions, only session 1 (S1), session 2 (S2), and session 3 (S3) were used. Session 4 video images were not used because the captured image of the face is not frontal as seen in Figure 1. The ChokePoint Dataset provided the eyes coordinates for their colour video images. All the frontal face images are cropped according to their given eyes coordinate and the eyes are aligned so that their eyes are in the same horizontal line. Figure 2 shows the face cropping template. Assuming $\mathrm{E}_{\mathrm{L}}$ is the length between the right and left eye and $\mathrm{M}$ is the middle point between the right and left eye, then the length from the right eye to $\mathrm{R}$, and from $\mathrm{M}$ to $\mathrm{T}$, as well as from the left eye to $\mathrm{L}$, is equal to $\mathrm{E}_{\mathrm{L}}$ and the length from $\mathrm{M}$ to $\mathrm{B}$ is $2 \mathrm{E}_{\mathrm{L}}$.

In our previous work (Dargham et al., 2015), the gray scale database provided by the ChokePoint Dataset was used while in this paper, the colour video images of the ChokePoint Dataset are used. The video frames were divided into three classes, namely; FAR, MEDIUM, and CLOSE. Each person has 18 frames per class. The first 18 frames from the 54 frames for each person are assigned to the FAR class. The next 18 frames after the FAR class frames are assigned to the MEDIUM class and the last 18 frames are assigned to the CLOSE class. A total of 4536 cropped video images with frontal face of a single person were used. Three databases representing three different session containing 1512 video images each were created. They represent 28 different persons. 14 persons are used for training and recall testing, and the other 14 different persons are used for reject testing only. The image size of the grayscale frontal face that ChokePoint Dataset provided is 96 by 96 pixels. Thus, in this work, the cropped video images will be set to 96 by 96 pixels. The grayscale and $\mathrm{YC}_{\mathrm{B}} \mathrm{C}_{\mathrm{R}}$ colour space image obtained from the colour video will be used in this work and the performance of both the gray scale and the $\mathrm{YC}_{B} \mathrm{C}_{R}$ will be compared. The colour channels that are investigated are the $C_{B}, C_{R}, C_{B}$ multiplied by $C_{R}$ $\left(C_{B} x C_{R}\right)$, the ratio of $C_{B}$ over $C_{R}\left(C_{B} / C_{R}\right)$, and the differences between $C_{B}$ and $C_{R}\left(C_{B}-C_{R}\right)$.

Jamal Ahmad Dargham, Ali Chekima, Ervin Gubin Moung and Segiru Omatu

A Comparison of the $Y_{C_{B}} C_{R}$ Colour Space with Gray Scale for Face Recognition for Surveillance Applications
ADCAIJ: Advances in Distributed Computing and Artificial Intelligence Journal Regular Issue, Vol. 7 N. 2 (2018), 43-52 eISSN: 2255-2863 - http://adcaij.usal.es Ediciones Universidad de Salamanca - CC BY NC DC 


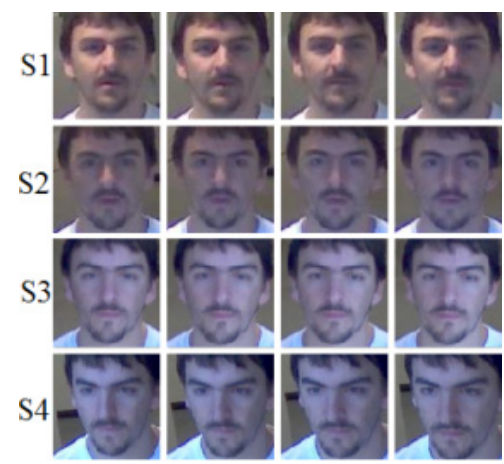

Figure 1: Samples of frontal face images in the P2L dataset, Source ChokePoint Dataset

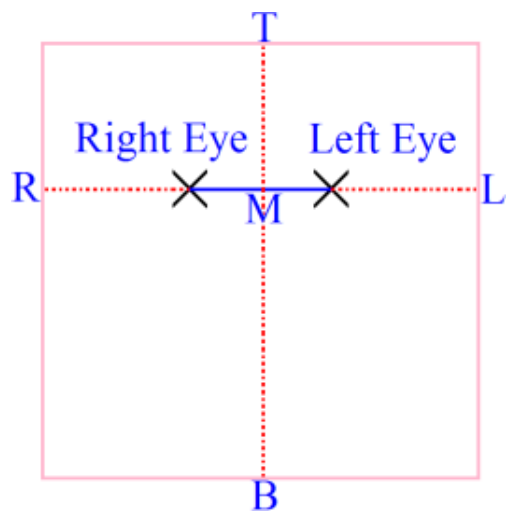

Figure 2: The face cropping template

\section{The Training and Testing Database}

In our previous work (Dargham et al., 2015), we have investigated the effect of training data selection on face recognition in surveillance application by using the provided gray scale images of the ChokePoint Dataset as our data. Eight cases of selecting training images were proposed. It was found that, Case 1 (using FAR class) gives the lowest performance while Case 8 gives the best performance followed by Case 6 . Thus, in this work Case 1, Case 6, and Case 8 selection methods will be used to create the training database. Table 1 shows the training database criteria while Table 2 shows the training database details for each cases.

Table 1: The proposed training database criteria

\begin{tabular}{c|l}
\hline Case & \multicolumn{1}{c}{ Selection criteria } \\
\hline 1 & $\begin{array}{l}\text { Three images per person randomly selected from the same class and from the same database ses- } \\
\text { sion will be used }\end{array}$ \\
\hline 6 & Nine images per person from all the database session with 1 mean image per class will be used. \\
\hline 8 & $\begin{array}{l}18 \text { images per person; consist of nine images and nine mean images from all the database session } \\
\text { with 1 randomly selected image and 1 mean image per class will be used. }\end{array}$ \\
\hline
\end{tabular}

Jamal Ahmad Dargham, Ali Chekima, Ervin Gubin Moung and Segiru Omatu

A Comparison of the $Y C_{B} C_{R}$ Colour Space with Gray Scale for Face Recognition for Surveillance Applications
ADCAIJ: Advances in Distributed Computing and Artificial Intelligence Journal Regular Issue, Vol. 7 N. 2 (2018), 43-52 elSSN: 2255-2863 - http://adcaij.usal.es Ediciones Universidad de Salamanca - CC BY NC DC 
Table 2: Training database details for case 1, 2, 3, 4, 5, 6, 7, and 8

\begin{tabular}{|c|c|c|c|c|c|}
\hline Case & $\begin{array}{c}\text { Training } \\
\text { database size }\end{array}$ & $\begin{array}{c}\text { Number of } \\
\text { persons in training } \\
\text { database }\end{array}$ & $\begin{array}{c}\text { Number of } \\
\text { images per } \\
\text { person }\end{array}$ & Number of class per person & $\begin{array}{c}\text { Number of } \\
\text { images per } \\
\text { class }\end{array}$ \\
\hline 1 & 42 images & 14 & 3 & 1 class, 1 session & 3 \\
\hline 6 & 126 images & 14 & 9 & 3 classes, all session & 1 \\
\hline 8 & 252 images & 14 & 18 & 3 classes, all session & 2 \\
\hline
\end{tabular}

Two testing databases were created. The first database, Client test database, has 756 images of the 14 persons for each session. This database will be used to test the recall capability of the face recognition system. The second database, Imposter test database, also has 756 images of 14 different persons for each session. This database will be used to test the rejection capability of the system.

\section{The Face Recognition System}

The face recognition system used in this work is the Principal Component Analysis (PCA) (Dargham et al., 2012; Turk et al., 2004) as shown in Figure 3. It consists of an offline training phase and an online testing phase. During the training phase, the entire set of training images are projected, using PCA, to a lower dimensional feature space. This projection will produce sets of feature vectors having much smaller dimensions compared to the original image dimensions. The feature vectors, a lower dimensional representation of the grayscale or YC${ }_{B} C_{R}$ are then stored in the training database. During the online recognition process, a test image is projected to a lower dimensional feature space using PCA. The feature vectors representing the test image are then compared with the feature vectors from the training database in the matching process.

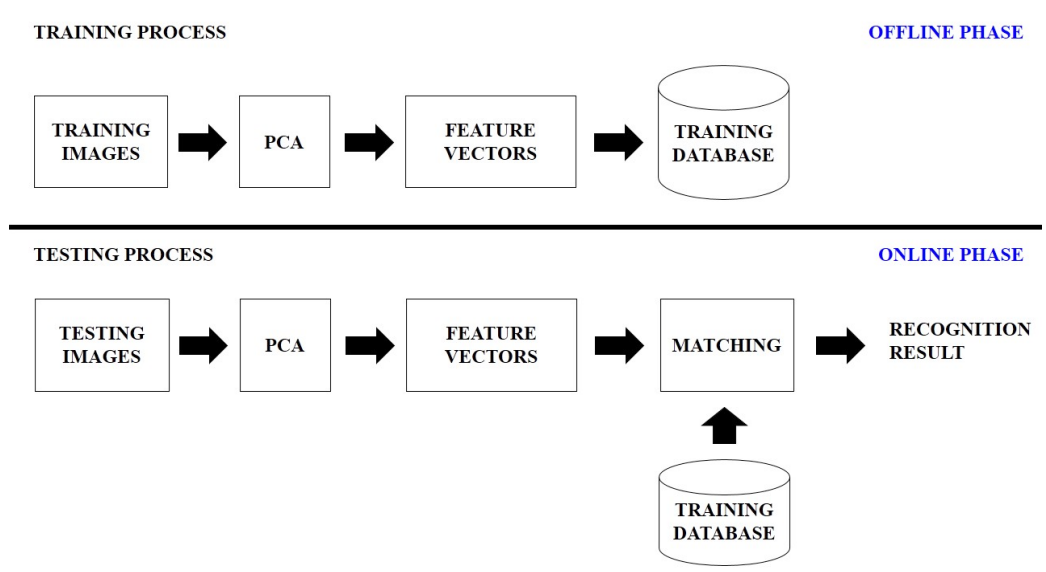

Figure 3: Block diagram of the PCA based face recognition system

\section{The Training Phase}

For the training and testing phases, the Euclidean distance, a popular distance measurement in biometric (Turk and Pentland, 1991; Zhao et al., 2003; Yoo et al., 2007), is used to calculate the distance between two vectors. In order to do the matching task during the testing phase, a formula generating a threshold value using the training

Jamal Ahmad Dargham, Ali Chekima, Ervin Gubin Moung and Segiru Omatu

A Comparison of the $Y_{B} C_{R}$ Colour Space with Gray Scale for Face Recognition for Surveillance Applications
ADCAIJ: Advances in Distributed Computing and Artificial Intelligence Journal Regular Issue, Vol. 7 N. 2 (2018), 43-52 eISSN: 2255-2863 - http://adcaij.usal.es Ediciones Universidad de Salamanca - CC BY NC DC 
database, denoted as, $t$, is proposed. Let $f$ be the feature vector from the training database, then, the threshold value, $t$, is the largest calculated Euclidean distance between any two feature vectors from the training database, denote as $\max \left\{|| f_{\mathrm{M}}-f_{\mathrm{N}} \mid\right\}$, divided by a tunable parameter denoted as Tcpara as shown in equation (1).

$$
t=\frac{\max \left\{\left\|f_{M}-f_{N}\right\|\right\}}{\text { Tcpara }}
$$

Where $M, N=1$ to $Z . M, N$ is the feature vector index in the training database and $Z$ is the size of the training database. The threshold value, $t$, will be used during the testing phase where it will be compared with a Euclidean distance value generated by the test person image during the matching task.

\section{The Testing Phase}

Let $i=1,2, \ldots 42$ and $M=1,2, \ldots Z$ and $Z$ is the size of the training database. Let $T_{\mathrm{R}}=\left\{f_{\mathrm{R} 1}, f_{\mathrm{R} 2}, \ldots, f_{\mathrm{R} 42}\right\}$ be the test person that have 42 test frames, $f_{\mathrm{Ri}}$ is a feature vector that represents the test person frame, and $f_{\mathrm{M}}$ is a feature vector from the training database, the minimum Euclidean distance between every test feature vector, $f_{\mathrm{Ri}}$, with all the training database feature vector $f_{\mathrm{M}}$, is calculated and denoted as $E=\left\{e_{1}, e_{2}, \ldots e_{42}\right\}$ where $E$ is a set that contain all the 42 minimum Euclidean distances and $e_{\mathrm{i}}$ is the minimum Euclidean distance calculated between $f_{\mathrm{Ri}}$ and $f_{\mathrm{M}}$. The person $P$ from the training database that has the minimum Euclidean distance $e_{\mathrm{i}}$ with the test feature vector $f_{\mathrm{Ri}}$, is denoted as $l_{\mathrm{i}}$ and the collection of $l_{\mathrm{i}}$ is $L=\left\{l_{1}, l_{2}, \ldots l_{42}\right\}$. Let $P_{\text {mode }}=\operatorname{mode}\{L\}$, be the highest occurrence from the set $L$, then the euclidean distance average, denoted as $E_{\mathrm{av}}$, of all the $e_{\mathrm{i}}$ from $E$ with $l_{\mathrm{i}}$ equal to $P_{\text {mode }}$, were calculated. If the average Euclidean distance between test person $T_{\mathrm{R}}$ and $P$ person in the training database, $E_{\mathrm{av}}\left(T_{\mathrm{R}}, P\right)$ is smaller than a given threshold $t$, then test person $T_{\mathrm{R}}$ and $P$ person in the training database are assumed to be of the same person. To measure the performance of both systems, several performance metrics are used. For a Recall test, if a test person $\boldsymbol{T i}$ is correctly matched to the same person $\boldsymbol{P i}$ in the training database, it is a Correct Recall. If a test person $\boldsymbol{T i}$ is incorrectly matched with person $\boldsymbol{P} \boldsymbol{j}$, where $\boldsymbol{i}$ and $\boldsymbol{j}$ are not the same person, it is a False Acceptance. If a test person $\boldsymbol{T} \boldsymbol{i}$ is of a person $\boldsymbol{P} \boldsymbol{i}$ in the training database but rejected by the system, it is a False Rejection. For a Reject test, if a test person $\mathbf{T i}$, from the Imposter test database is rejected by the face recognition system, it is a Correct Reject. If a test person $\boldsymbol{T i}$ from the Imposter test database is accepted by the program, it is a False Acceptance. Let NCR = number of correct recall, NCJ = number of correct reject, and NT $=$ number of test, then Correct Recall Rate $=$ NCR/NT and Correct Reject Rate $=\mathrm{NCJ} / \mathrm{NT}$. For this work, the threshold tuning parameter, Tcpara, was set so that the system has equal correct rates for both recall and reject. This classification rate is defined as the Equal Correct Rate (ECR).

\section{Data Fusion Strategy}

The fusion strategy fused the outputs from two or more face recognition systems. The logic operator chosen for the data fusion strategy is the OR operator. For the recall test, if at least one system give a correct matching and the other system(s) give wrong matching or not found, then a correct match is found. Otherwise, the fusion system will give a no match is found. For the reject test, if at least one system give a correct reject and the other system(s) give false acceptance, then the fusion system gives a correct reject. Otherwise, the fusion system will give a false acceptance. The use of AND operator will make the fusion strategy become more strict, for example, for a recall test, all the individual system need to give a correct match found in order for the fusion system to give a correct match found. Thus, the OR operator were selected since it require at least one system to give a TRUE statement for the fusion system to give TRUE statement too.

Jamal Ahmad Dargham, Ali Chekima, Ervin Gubin Moung and Segiru Omatu

A Comparison of the $\mathrm{YC}_{\mathrm{B}} \mathrm{C}_{\mathrm{R}}$ Colour Space with Gray Scale for Face Recognition for Surveillance Applications
ADCAIJ: Advances in Distributed Computing and Artificial Intelligence Journal Regular Issue, Vol. 7 N. 2 (2018), 43-52 eISSN: 2255-2863 - http://adcaij.usal.es Ediciones Universidad de Salamanca - CC BY NC DC 


\section{Results and Discussion}

Each experiment for each of the cases was carried out 10 times and the average of the recognition rates from the 10 experiment runs is used for comparison. Figure 4 shows the performance of the gray scale with individual channels of the $\mathrm{YC}_{B} \mathrm{C}_{R}$. As can be seen, from Figure 4, the grayscale always outperform the other five $\mathrm{YC}_{B} \mathrm{C}_{R}$ channels, giving $76.41 \%, 100 \%$, and $100 \%$ rate in case 1,6 , and 8 respectively. Comparing the colour channels, it was found that the $\mathrm{C}_{\mathrm{B}} \mathrm{x} \mathrm{C}_{\mathrm{R}}$ channel always outperform the other channels for all the cases tested. From the results of case 1, it can be seen that the $C_{B}, C_{R}, C_{B} / C_{R}$, and $C_{B}-C_{R}$ channels are not suitable when only three images from one class are used for training as all of them give an equal error rate below $50 \%$. As can be seen from Figure 4, the performance of all channels improves as the number of images per person increases from 3 images in case 1, to 9 images in case 2 and then to 18 images in case 3.

The fusions of several channels from the $\mathrm{YC}_{B} \mathrm{C}_{\mathrm{R}}$ colour space are also carried out to investigate whether or not the fusion strategy can compete with the gray scale performance. The proposed fusion strategies are shown in Table 3. The average rate of the recall and reject rates given by the fusion strategy is used for comparison and is shown in Figure 5.

As can be seem from Figure 4 and Figure 5, the fusion of two or more channels always gives better performance than the individual channel regardless of the number of images used for training or the data set from which they are selected. As can be seen from Figure 5, the fusion of the two best channels slightly outperforms the gray scale for case 1. In addition, as the number of fused channels increases so does the performance of the system albeit not at the same rate.

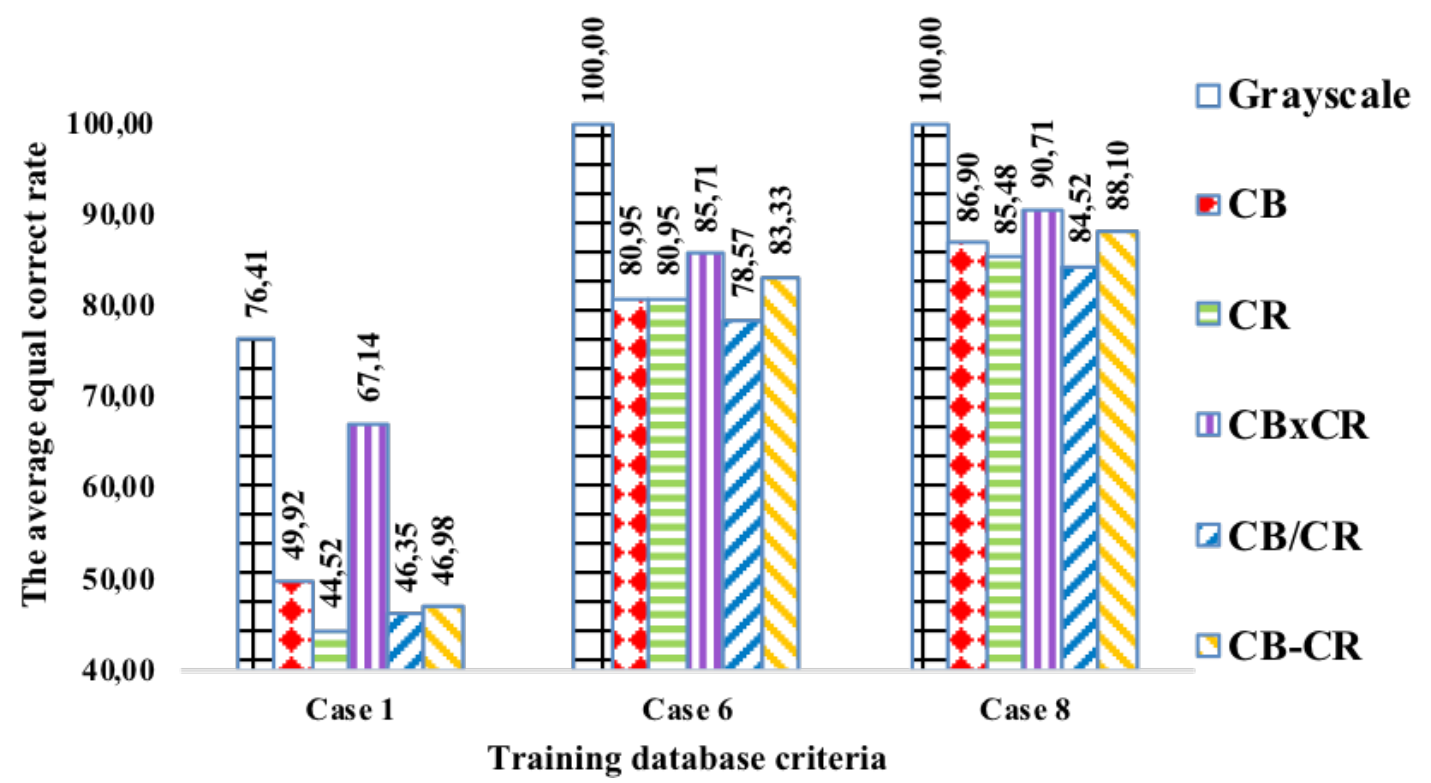

Figure 4: The average equal correct rate for the individual colour channels compared to that of the gray scale

Jamal Ahmad Dargham, Ali Chekima, Ervin Gubin Moung and Segiru Omatu

A Comparison of the $Y C_{B} C_{R}$ Colour Space with Gray Scale for Face Recognition for Surveillance Applications
ADCAIJ: Advances in Distributed Computing and Artificial Intelligence Journal Regular Issue, Vol. 7 N. 2 (2018), 43-52 eISSN: 2255-2863 - http://adcaij.usal.es Ediciones Universidad de Salamanca - CC BY NC DC 
Table 3: The proposed fusion strategy

\begin{tabular}{|c|c|c|c|}
\hline & Case 1 & Case 6 & Case 8 \\
\hline Fusion of the two highest rate & $\mathrm{C}_{\mathrm{B}}, \mathrm{C}_{\mathrm{B}} \mathrm{xC}_{\mathrm{R}}$ & $\begin{array}{l}\mathrm{C}_{\mathrm{B}} \mathrm{x} \mathrm{C}_{\mathrm{R}} \\
\mathrm{C}_{\mathrm{B}}-\mathrm{C}_{\mathrm{R}}\end{array}$ & $\begin{array}{l}\mathrm{C}_{\mathrm{B}} \mathrm{x} \mathrm{C}_{\mathrm{R}} \\
\mathrm{C}_{\mathrm{B}}-\mathrm{C}_{\mathrm{R}}\end{array}$ \\
\hline Fusion of the three lowest rate & $\begin{array}{l}\mathrm{C}_{\mathrm{R}}, \mathrm{C}_{\mathrm{B}} / \mathrm{C}_{\mathrm{R}} \\
\mathrm{C}_{\mathrm{B}}-\mathrm{C}_{\mathrm{R}}\end{array}$ & $\mathrm{C}_{\mathrm{B}}, \mathrm{C}_{\mathrm{R}}, \mathrm{C}_{\mathrm{B}} / \mathrm{C}_{\mathrm{R}}$ & $\mathrm{C}_{\mathrm{B}}, \mathrm{C}_{\mathrm{R}}, \mathrm{C}_{\mathrm{B}} / \mathrm{C}_{\mathrm{R}}$ \\
\hline Fusion of the three highest rate & $\begin{array}{l}\mathrm{C}_{\mathrm{B}}, \mathrm{C}_{\mathrm{B}} \mathrm{xC}_{\mathrm{R}} \\
\mathrm{C}_{\mathrm{B}}-\mathrm{C}_{\mathrm{R}}\end{array}$ & $\begin{array}{l}\mathrm{C}_{\mathrm{B}}, \mathrm{C}_{\mathrm{B}} \mathrm{xC}_{\mathrm{R}} \\
\mathrm{C}_{\mathrm{B}}-\mathrm{C}_{\mathrm{R}}\end{array}$ & $\begin{array}{c}\mathrm{C}_{B}, \mathrm{C}_{\mathrm{B}} \mathrm{x} \mathrm{C}_{\mathrm{R}} \\
\mathrm{C}_{\mathrm{B}}-\mathrm{C}_{\mathrm{R}}\end{array}$ \\
\hline $\begin{array}{l}\text { Fusion of the one highest rate and two } \\
\text { lowest rate }\end{array}$ & $\mathrm{C}_{\mathrm{R}}, \mathrm{C}_{\mathrm{B}} \mathrm{x} \mathrm{C}_{\mathrm{R}}, \mathrm{C}_{\mathrm{B}} / \mathrm{C}_{\mathrm{R}}$ & $\mathrm{C}_{\mathrm{R}}, \mathrm{C}_{\mathrm{B}} \mathrm{x} \mathrm{C}_{\mathrm{R}}, \mathrm{C}_{\mathrm{B}} / \mathrm{C}_{\mathrm{R}}$ & $\frac{\mathrm{C}_{\mathrm{R}}, \mathrm{C}_{\mathrm{B}} \mathrm{x} \mathrm{C}_{\mathrm{R}}, \mathrm{C}_{\mathrm{B}} /}{\mathrm{C}_{\mathrm{R}}}$ \\
\hline Fusion of all the five channels & All channels & All channels & All channels \\
\hline
\end{tabular}

It can also be seen that the fusion of channels that individually gives good performance will give higher performance that fusing those with lower performance. This suggests that the performance of the individual channel is an important criterion when selecting channels for fusion. In Case 6 and 8 however, the gray scale outperforms all the proposed fusion strategies. This shows that using one image and one mean image from each class from all the database sessions gives the best performance in term of accuracy and process time since converting RGB to gray scale is faster than converting $R G B$ to $\mathrm{YC}_{B} \mathrm{C}_{\mathrm{R}}$.

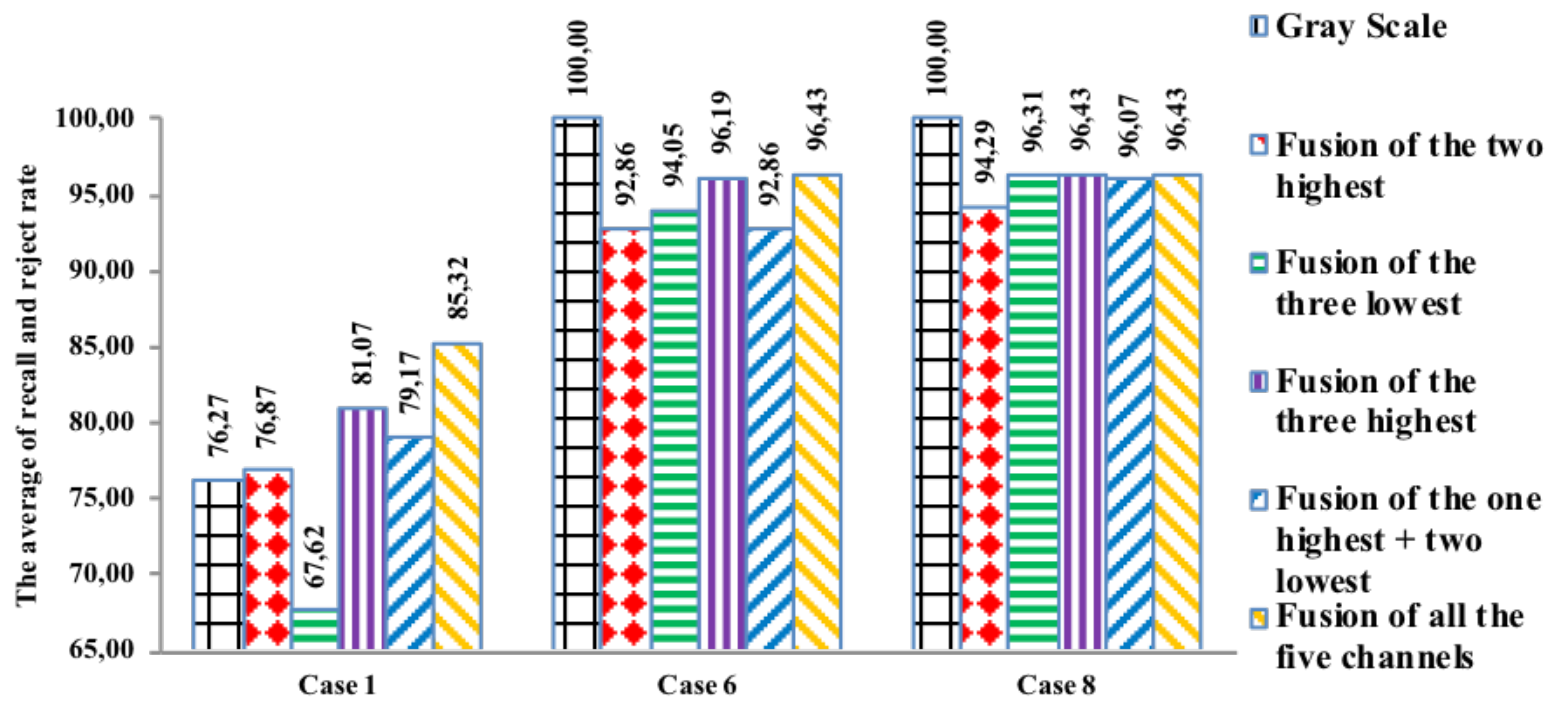

Figure 5: The recognition performance of the data fusion

The results of the individual channels and their fusions, shown in Figure 4 and Figure 5, are new results which were not reported in our previous work (Dargham et al., 2015). However, the results of the gray scale shown in Figure 4 and in (Dargham et al., 2015) are for the same cases. The reason that they had different recognition rates is because of the different training data set used. Nevertheless, the same performance pattern is shown in both works where Case 1 gives the lowest performance while Case 8 gives the best performance.

The results shown in figures 4 and 5 gives rise to an interesting question why some channels gives better results that the other channels. By comparing the grayscale, $C_{B}$, and $C_{R}$ channels from the same image, using human eye observation, one conclusion can be made is that in any image, the important edges or visual features are clearer in gray scale compared to the $C_{B}$ and $C_{R}$ channels. This statement is also supported by (John Zhang,

Jamal Ahmad Dargham, Ali Chekima, Ervin Gubin Moung and Segiru Omatu

A Comparison of the $Y_{C_{B}} C_{R}$ Colour Space with Gray Scale for Face Recognition for Surveillance Applications
ADCAIJ: Advances in Distributed Computing and Artificial Intelligence Journal Regular Issue, Vol. 7 N. 2 (2018), 43-52 eISSN: 2255-2863 - http://adcaij.usal.es Ediciones Universidad de Salamanca - CC BY NC DC 
2012) and (Rethunk, 2012). For face recognition, the facial features are important for recognition. Figure 6 shows the average number of edges obtained from the mean face image from all the database sessions for grayscale, $\mathrm{C}_{\mathrm{B}}, \mathrm{C}_{\mathrm{R}}, \mathrm{C}_{\mathrm{B}} \mathrm{xC}_{\mathrm{R}}, \mathrm{C}_{\mathrm{B}} / \mathrm{C}_{\mathrm{R}}$, and $\mathrm{C}_{\mathrm{B}}-\mathrm{C}_{\mathrm{R}}$ by using the MATLAB function, edge(image), for case 1, 6, and 8 .

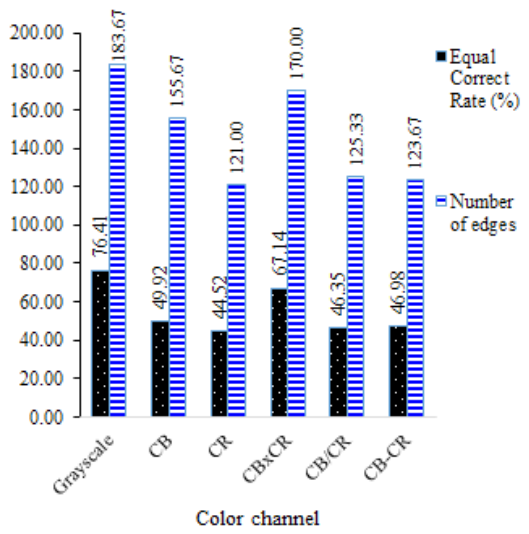

(a)

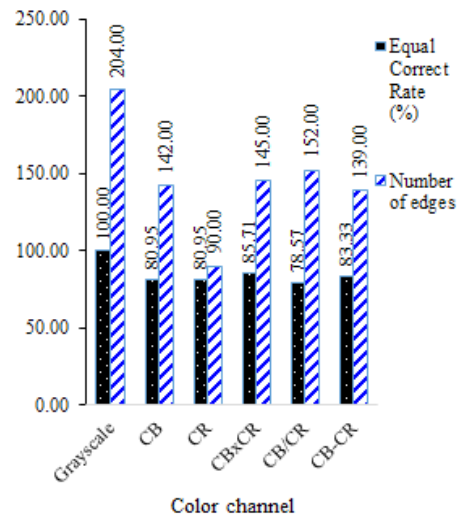

(b)

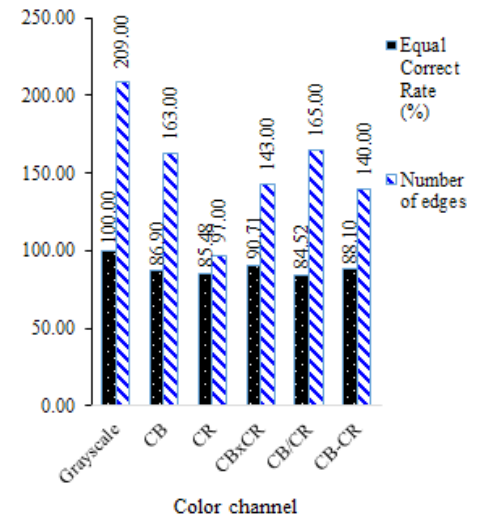

(c)

Figure 6: The equal correct rate and the number of edges for (a) Case 1, (b) Case 6, and (c) Case 8

As can be seen from figure 6, from Case 1, when only three images from one class are used for training, we see that the colour spaces with higher number of edges tend to give better recognition results. Gray scale has the highest number of edges, and as shown in figure 6, it gave the best recognition performance. Among the $C_{B} C_{R}$ colour spaces, $C_{B} x_{R}$ has the highest edges and also has the highest recognition performance as seen in figure 4. It can be seen that $C_{B} / C_{R}$ and $C_{B}-C_{R}$ has similar number of edges, and their recognition performance is similar too. Overall, for Case 1, the number of edges chart pattern is similar to the average equal correct rate chart pattern.

Also from figure 6, for case 6 and case 8, we can see that the gray scale always has the highest number of edges compare to the other channels and gray scale also has the best recognition performance, same as in case 1. Comparing the gray scale edges in case 1, 6, and 8 also shows an increasing number of edges. This shows that using the gray scale representation, as the number of images used in the training database increases, it can increase the quality of the mean face that were used for the PCA function, thus resulting a better quality of eigenface. Also from figure 6 , for case 6 and 8 , by comparing the $C_{B}$ and $C_{R}$, it can be seen that $C_{B}$ has higher number of edges compare to $C_{R}$, and as shown in figure $4, C_{B}$ also has better performance compare to $C R$, except for case 6 where both of them has the same recognition rate. For the case 6 and case 8 , although the number of edges chart pattern and the average equal correct rate chart pattern for $C_{B}$ and $C_{R}$ shows similar pattern, the number of edges has little effect on the recognition performance. But for $C_{B} x_{R}, C_{B} / C_{R}$, and $C_{B}-C_{R}$, there are no direct relation that can be made by comparing the number of edges and their recognition performance shown in figure 4. This could mean that, if a mean image was used in the training database (case 6 and case 8 both uses mean images in their training database), the number of edges has no positive effect on $C_{B} x_{R}, C_{B} / C_{R}$, and $C_{B}-C_{R}$ recognition performance.

\section{Conclusion}

In this work, an investigation of the performance of different channels of the $\mathrm{YC}_{\mathrm{B}} \mathrm{C}_{\mathrm{R}}$ colour space on face recognition for surveillance applications has been carried out. It was found that, the gray scale gives better performance than any of the individual colour channel regardless of the cases used. However, the fusion of $\mathrm{C}_{\mathrm{B}} \mathrm{xC}_{\mathrm{R}}$ with any other channel outperforms the gray scale when three images of the same class from the same database were used for training (Case 1). For the $\mathrm{YC}_{\mathrm{B}} \mathrm{C}_{\mathrm{R}}$ colour space, the best performance is achieved by

Jamal Ahmad Dargham, Ali Chekima, Ervin Gubin Moung and Segiru Omatu

A Comparison of the $Y C_{B} C_{R}$ Colour Space with Gray Scale for Face Recognition for Surveillance Applications
ADCAIJ: Advances in Distributed Computing and Artificial Intelligence Journal Regular Issue, Vol. 7 N. 2 (2018), 43-52 eISSN: 2255-2863 - http://adcaij.usal.es Ediciones Universidad de Salamanca - CC BY NC DC 
using the $C_{B} x C_{R}$ channel. The $C_{B}, C_{R}, C_{B} / C_{R}$, and $C_{B}-C_{R}$ are not suitable to be used when the number of training images per person is small. It was also found that if the differences between individual channels performance vary significantly, the individual channel performance become an important criteria when selecting channels for fusion. It was also found that, for face recognition system where facial features are crucial for the recognition, the gray scale is the better choice since it contain better quality of edges and visual information compare to the other $\mathrm{C}_{\mathrm{B}} \mathrm{C}_{\mathrm{R}}$ channels.

\section{References}

Chaves-González, J. M., Vega-Rodríguez, M. A., Gómez-Pulido, J. A., Sánchez-Pérez, J. M., 2010. Detecting skin in face recognition systems A colour spaces study, Digital Signal Processing, Volume 20, Issue 3, pages 806-823.

Chelali, F.Z., Cherabit, N., Djeradi, A., 2015. Face recognition system using skin detection in RGB and YCBCR colour space, Web Applications and Networking (WSWAN), 2nd World Symposium, pages 1-7.

Dargham, J., Chekima, A., Moung, E., and Omatu, S, 2015. The Effect of Training Data Selection on Face Recognition in Surveillance Application, Advances In Distributed Computing And Artificial Intelligence Journal, Volume 3, pages 58-66.

Dargham, J., Chekima, A., and Moung, E., 2012. Fusion of PCA and LDA Based Face Recognition System, International Conference on Software and Computer Applications, IPCSIT Volume 41.

Karimi, B. and Devroye, L., 2007. A Study on Significance of Colour in Face Recognition using Several Eigenface Algorithms, Canadian Conference Electrical and Computer Engineering (CCECE), pages 1309-1312.

National ICT Australia Limited, 2014. http://arma.sourceforge.net/chokepoint/

Rethunk, 2012. Why we should use gray scale for image processing? [Online forum comment]. Message posted to http://stackoverflow.com/questions/12752168/why-we-should-use-gray-scale-for-image-processing.

Turk, M. and Pentland, A., 1991. Eigenfaces for Recognition, Journal of Cognitive Neuroscience, Volume 3, pages 71-86.

Yoo, S., Park, R. and Sim, D., 2007. Investigation of Colour Spaces for Face Recognition, In Proceedings of Machine Vision Application, pages 106-109.

Zhang, J., 2012. Computer Vision: If you had to choose, would you rather go without luminance or chrominance? [Online forum comment]. Message posted to https://www.quora.com/Computer-Vision/Computer-Vision-If-you-had-to-choose-would-you-rather-go-without-luminance-or-chrominance/answer/ John-Zhang

Zhao, W., Chellappa, R., Phillips, P. J., Rosenfeld, A., 2003. Face recognition: A literature survey, ACM Computing Surveys (CSUR), Volume 35, Issue 4, pages 399-458.

Jamal Ahmad Dargham, Ali Chekima, Ervin Gubin Moung and Segiru Omatu

A Comparison of the $\mathrm{YC}_{\mathrm{B}} \mathrm{C}_{\mathrm{R}}$ Colour Space with Gray Scale for Face Recognition for Surveillance Applications
ADCAIJ: Advances in Distributed Computing and Artificial Intelligence Journal Regular Issue, Vol. 7 N. 2 (2018), 43-52 eISSN: 2255-2863 - http://adcaij.usal.es Ediciones Universidad de Salamanca - CC BY NC DC 
